Frankena, T.K., Naaldenberg, J., Bekkema, N., Schrojenstein Lantman-de Valk, H.J.M. van, Cardol, M., Leusink, G. An exploration of the participation of people with intellectual disabilities in research: a structured interview survey. Journal of Applied Research in Intellectual

Disabilities: 2018, 31(5), 942-947

\begin{tabular}{|l|l|}
$\begin{array}{l}\text { Postprint } \\
\text { Version }\end{array}$ & 1.0 \\
\hline Journal website & https://onlinelibrary.wiley.com/doi/pdf/10.1111/jar.12453 \\
\hline Pubmed link & https://www.ncbi.nlm.nih.gov/pubmed/29608236 \\
\hline DOI & $10.1111 /$ jar.12453 \\
\hline
\end{tabular}

This is a NIVEL certified Post Print, more info at http://www.nivel.eu

\title{
An exploration of the participation of people with intellectual disabilities in research-a structured interview survey.
}

Frankena, T.K., NAALDENBERG, J., BeKKEMA, N., Schrojenstein LANTMAN-DE VALK, H.J.M. VAN, CARDOL, M., LEUSINK, G.

\begin{abstract}
Background: Even though participation of people with intellectual disabilities in research is increasingly common, there is little insight into how many people with intellectual disabilities participate, their motivations to participate and their interests regarding study results.

Method: Five questions were added to the Panel Living Together (PLT) survey among 508 people with intellectual disabilities. The questions aimed to gain insight into the (i) frequency of participation; (ii) methods used to participate; (iii) motivations to participate; and (iv) interests regarding study results.

Results: Although $73.5 \% \quad(\mathrm{n}=347)$ of the respondents enjoyed their participation and $71.6 \%(\mathrm{n}=312)$ found it important to participate, only $11.8 \%$ $(n=60)$ participated in research other than PLT. Of the respondents, 61\% $(\mathrm{n}=261)$ indicated they wanted to be informed about study results, $29.1 \%$ $(n=148)$ of this group stated they wanted to compare, learn and share information.

Conclusions: Future research should focus on how motivations of people with intellectual disabilities to participate in inclusive research, such as "empowerment," can be supported to facilitate their involvement in research.
\end{abstract}

\section{INTRODUCTION}

Participation of people with intellectual disabilities in research, both as consultants as well as collaborators, is an emergent topic (Puyalto, Pallisera, Fullana, \& Vila, 2015). This is in line with the United Nation's Convention on the Rights of Persons with Disabilities (UNCRPD) and British Disability Studies movement's motto "nothing about us without us," which strive for people with intellectual disabilities participation in all aspects of life (Shakespeare \& Watson, 2002; United Nations, 2006). Another movement contributing to the increase in people with intellectual 
Frankena, T.K., Naaldenberg, J., Bekkema, N., Schrojenstein Lantman-de Valk, H.J.M. van, Cardol, M., Leusink, G. An exploration of the participation of people with intellectual disabilities in research: a structured interview survey. Journal of Applied Research in Intellectual Disabilities: 2018, 31(5), 942-947

disabilities participation in research is the "inclusive research movement." The term inclusive research was coined by Walmsley and Johnson and defined as: "research which includes or involves people with learning disabilities as more than just subjects of research" (Walmsley \& Johnson, 2003), p. 61. It is based on the principles that: (i) the research topics studied matter to people with intellectual disabilities; (ii) the research presents people with intellectual disabilities' perspective; and (iii) that people with intellectual disabilities are treated with respect (Nind \& Vinha, 2014; Walmsley \& Johnson, 2003). Inclusive research has its roots in the 1950s, where health service users demanded to have a voice in medical decisions affecting them. This evolved in health service users' involvement through participatory research (Wilson et al., 2015), including people with intellectual disabilities. Over the past decades, two generations of inclusive research developed. The first generation confirmed and addressed the need for inclusive research. The second generation started more recently with a focus on outcomes, added value, effective methods and partnerships and benefits for both individuals and research teams (Grant \& Ramcharan, 2007).

People with intellectual disabilities can participate in research in several ways. Firstly, they can participate by means of consultation through, for example, questionnaires or interviews, which means people with intellectual disabilities are respondents or subjects of research. Secondly, they can participate by means of collaboration or control through, for example, the role of advisory board member or co-researcher, which are more inclusive manners of participation (INVOLVE, 2014). Despite the increased focus on participation of people with intellectual disabilities in research, it has mostly been approached from an academic perspective and is only limited discussed with people with intellectual disabilities themselves (Puyalto et al., 2015). Insight into participation in research mainly focuses on individual experiences from co-researchers who have participated in a collaborative manner (Nind \& Vinha, 2014). Little insight exists beyond individual experiences, for instance into the frequency in which people with intellectual disabilities participate in research, the way they participated and the extent to which participation fits their needs and interests. This study aims to contribute to this insight by involving the Dutch Panel Living Together, existing of 508 people with intellectual disabilities. The objective of this brief report is to explore the participation of people with intellectual disabilities in research by means of a structured interview survey amongst people with intellectual disabilities regarding: (i) frequency of participation; (ii) methods used to participate; (iii) motivations to participate; and (iv) interests regarding study results.

\section{METHOD}

\subsection{Panel living together}

Questions on "participation in research" were added to the Panel Living Together (PLT) questionnaire, which was established as part of a Dutch national research programme on community participation of people with intellectual disabilities in 2006 by the National Institute of Health Services Research (NIVEL). PLT consists of approximately 550 people with intellectual disabilities and 400 (in)formal carers, living in the Netherlands who were recruited via ambulatory care providers for people with intellectual disabilities and general practitioners. PLT members were 
Frankena, T.K., Naaldenberg, J., Bekkema, N., Schrojenstein Lantman-de Valk, H.J.M. van, Cardol, M., Leusink, G. An exploration of the participation of people with intellectual disabilities in research: a structured interview survey. Journal of Applied Research in Intellectual Disabilities: 2018, 31(5), 942-947

included if they (i) were 15 years or older and (ii) had mild to moderate intellectual disabilities (Cardol, Speet, \& Rijken, 2007). A structured interview survey is conducted biannually among PLT members with intellectual disabilities covering the topics: living; leisure; work and daily activities; social contacts; finances; and Internet. The survey is conducted face-to-face by trained interviewers at the respondents' preferred locations. In $74 \%$ of the interviews, (in)formal carers assisted respondents. In November 2014, the survey included questions on the topic "participation in research." PLT offers the opportunity to use data on respondents' descriptives such as sex, age and level of intellectual disabilities (NIVEL, 2015). PLT is registered with the Dutch Data Protection Authority (registration number 1342229), and data are collected according to the Authority's privacy protection guidelines (Dusseljee, Rijken, Cardol, Curfs, \& Groenewegen, 2010). This paper addresses the results on the topic "participation in research" only.

\section{[BOX 1]}

\subsection{Survey questions}

Survey questions were compiled in collaboration with two co-researchers with intellectual disabilities and a PLT researcher (NB). The co-researchers and lead researcher discussed the PLT, its participants, and topics of interest to the coresearchers during several meetings over the course of 2 months. Recurring themes during these discussions were: "how many," "how" and "why" people with intellectual disabilities participated in research. Additionally, one of the coresearchers elaborated upon her personal experience while participating in research, where she received no feedback afterwards. She wondered whether other people with intellectual disabilities experienced the same. Eventually, the co-researchers and lead researcher agreed on the topics: (i) frequency of participation, (ii) methods used to participate, (iii) motivation to participate and (iv) interests regarding study results. The PLT researcher provided input through e-mail correspondence on how questions, explanations and examples could be formulated. Additionally, literature was used to contribute to the answer categories. The final questions are listed in Box 1. In order to try to prevent socially desirable answers, respondents were not obliged to answer the questions to continue with the survey; however, this cannot entirely be prevented.

\subsection{Data analysis}

Data from multiple-choice questions 1-4 were analysed using descriptive statistics (SPSS Statistics 20) by computing them into percentages per response category. Questions 1 and 4 consisted of four answer categories: "yes," "no," "I don't know" and "I can't answer the question." Data from the open-ended question 5 were quantified and categorized. All questions have missing data as respondents were not obliged to answer every question to complete the survey, and, therefore, valid percentages and number of respondents are presented as results.

\section{RESULTS}

A total of 508 respondents completed the entire PLT survey in 2014, of which 289 were men (56.9\%). Respondents' descriptives are presented in Table 1. 
Frankena, T.K., Naaldenberg, J., Bekkema, N., Schrojenstein Lantman-de Valk, H.J.M. van, Cardol, M., Leusink, G. An exploration of the participation of people with intellectual disabilities in research: a structured interview survey. Journal of Applied Research in Intellectual Disabilities: 2018, 31(5), 942-947

\section{[TABLE 1]}

\subsection{Frequency of participation and ways to participate}

Of the 508 respondents, $60(11.8 \%)$ respondents indicated they were involved in research other than PLT surveys, 350 (68.9) respondents stated they did not participate in other research, 65 (12.8\%) respondents did not know whether they participated in other research and $33(6.5 \%)$ respondents could not answer the question. Table 2 presents the frequency of participation by respondents who have indicated to have participated in research other than PLT surveys $(n=60 ; 11.8 \%)$. The majority of these respondents participated through consultation. Several respondents participated through collaboration, with advisory boards $(43.3 \%)$ being the most frequent.

\section{[TABLE 2]}

\subsection{Motivation to participate}

Nearly all respondents $(n=471 ; 92.7 \%)$ answered the question on their motivation to participate in research. The majority indicated that they did so because they (1) expected to enjoy it $(n=347 ; 73.5 \%)$ and $(2)$ found research important $(n=312$; $71.6 \%)$. For all motivations except "enjoy it," the answer category "I don't know" is relatively high (Table 3 ).

\section{[TABLE 3]}

\subsection{Interests regarding study results}

Of the 428 respondents who have completed question 4, $261(61.0 \%)$ indicated interest in the results of studies to which they contributed, $100(23.4 \%)$ did not find it important, 66 (15.4\%) did not know whether they found it important and one respondent $(0.2 \%)$ could not answer this question. Of the respondents who wanted to receive results, $148(29.1 \%)$ answered question 5. Answers to the open-ended question included a desire to receive as many study results as possible, because they were curious and interested. They wanted to use the results to compare themselves with others, learn from the results and share the information with others.

\section{DISCUSSION}

This structured interview survey aimed to explore the participation of people with intellectual disabilities in research. Although $73.5 \%(n=347)$ of the respondents enjoyed their participation and $71.6 \%$ found it important to participate $(n=312)$, only $11.8 \%(n=60)$ participated in research other than PLT. Of the respondents who answered question 2 on participation methods $(n=60)$, only $43.3 \%(n=26)$ participated as an advisory board member and $11.7 \%(n=7)$ as a co-researcher, which are seen as inclusive research methods (Frankena, Naaldenberg, Cardol, Linehan, \& Lantman Van Schrojenstein de Valk, 2015). To our knowledge, no data exist on the frequency of participatory research with other patient groups or the general population, making comparison difficult. This study did not examine why people with intellectual disabilities did not participate in other studies (e.g., no opportunities or interest to participate). Additionally, when looking at inclusive research's definition, the emphasis is on how people with intellectual disabilities are 
Frankena, T.K., Naaldenberg, J., Bekkema, N., Schrojenstein Lantman-de Valk, H.J.M. van, Cardol, M., Leusink, G. An exploration of the participation of people with intellectual disabilities in research: a structured interview survey. Journal of Applied Research in Intellectual Disabilities: 2018, 31(5), 942-947

included (e.g., "as more than just subjects of research"), not on how many people are involved. Nonetheless, these percentages do not reflect the aim of inclusive research, where people with intellectual disabilities should have the chance to be actively involved (Walmsley \& Johnson, 2003). The definition of inclusive research by Walmsley and Johnson (2003) leaves a lot of room for interpretation (Bigby, Frawley, \& Ramcharan, 2014; Blunt et al., 2012), and researchers can have their own perception and interpretation of such research, resulting in a variety of inclusive methods.

This study provides insight into the motivations of people with intellectual disabilities to participate in research. Respondents in this study scored several motivations relatively highly (i.e., expecting to enjoy it, finding research important, learning from it, becoming a more confident person, and having something to do). In studies on experiences of co-researcher, topics such as increasing self-esteem, increasing social capital, learning new skills, and expressing yourself were mentioned as motivations to participate in research (Beighton et al., 2017; Puyalto et al., 2015), which correspond with findings from this study. A recent literature review comparing 26 studies applying inclusive research on characteristics including motivations found that many researchers expect "empowerment" to be people with intellectual disabilities's core motivation to participate in research (Frankena et al., 2015). Empowerment might partly be a motivation for people with intellectual disabilities to participate in research — captured in topics such as learning new skills and increasing social capital; however, this is not the sole reason for people with intellectual disabilities to participate in research. Furthermore, $61 \%$ of the respondents expressed interests in the studies they participated in. Responding to these motivations and interests is a sign of commitment towards people with intellectual disabilities and greater attention should be given to this, expecting that it improves research. As a result of improved research through participation, we expect that the health care and overall quality of life of people with intellectual disabilities can improve through meaningful dialogue with this group.

\subsection{Strengths and limitations}

Questions were developed in collaboration with two co-researchers with intellectual disabilities. However, trained interviewers indicated that some respondents found these interview questions difficult to answer and the topic complicated. Interviewing people with intellectual disabilities can be challenging because of the risk of response bias, acquiescence, recency and nay-saying (Finlay, 2015; Finlay \& Lyons, 2001). Thus, for future research purposes, methods should be explored to increase accessibility of the topic "participation in research," in order for people with intellectual disabilities to be able to contribute meaningfully to research. One of these methods is developing accessible information in collaboration with co-researchers with intellectual disabilities.

The respondents in this study are not representative of the entire intellectual disabilities population in the Netherlands. People with more intellectual disabilities are excluded from PLT because of communication challenges, and, therefore, results cannot be generalized to people with severe and profound intellectual disabilities. Additionally, PLT consists of a select group of people with intellectual disabilities of which the majority has participated in previous PLT surveys and are more likely to have participated in other research. Thus, the frequency of their participation in research other than PLTs might be higher than that of the general population with 
Frankena, T.K., Naaldenberg, J., Bekkema, N., Schrojenstein Lantman-de Valk, H.J.M. van, Cardol, M., Leusink, G. An exploration of the participation of people with intellectual disabilities in research: a structured interview survey. Journal of Applied Research in Intellectual Disabilities: 2018, 31(5), 942-947

mild to moderate intellectual disabilities. This is worrisome for the frequency of participation in research for the whole population with intellectual disabilities, as this is possibly even lower. However, because of PLT respondents' ability to speak from experience, their contribution on this scarcely researched topic is important. Moreover, this is one of first quantitative explorations of the participation of people with intellectual disabilities in research from people with intellectual disabilities perspective. Future research should deepen the understanding of how people with intellectual disabilities can actively participate in research, especially through inclusive research methods, as this is expected to improve their health, health care and quality of life.

\section{CONCLUSION}

This structured interview survey has given initial insight into people with intellectual disabilities' participation in research. A minority of the respondents participated in research other than PLT, even less participated through inclusive methods, despite their response that they found research enjoyable and important. Almost half of the respondents indicated that they wanted to learn from research. Researchers' assumptions about people with intellectual disabilities' motivation to participate only partly concur with their actual motivation to participate. This calls for meaningful collaboration between people with intellectual disabilities and academics to explore each others' preferences, needs and motivations.

\section{ACKNOWLEDGMENTS}

We would like to thank co-researchers Anneke van der Cruijsen and Simon Wilting for their contribution to this structured interview survey. In addition, we are very grateful to PLT respondents, interviewers, and researchers who made this study possible. Furthermore, we would like to thank NIVEL for the opportunity to be part of the 2014 PLT survey. Moreover, we are thankful for the support of the Consortium Stronger On Your Own Feet.

\section{CONFLICT OF INTEREST}

All authors declare no conflict of interest.

\section{REFERENCES}

Beighton, C., Victor, C., Carey, I. M., Hosking, F., DeWilde, S., Cook, D. G., Manners, P., \& Harris, T. (2017). 'I'm sure we made it a better study...': Experiences of adults with intellectual disabilities and parent carers of patient and public involvement in a health research study. Journal of Intellectual Disabilities, 1-19. https://doiorg.proxy.library.uu.nl/10.1177/1744629517723485

Bigby, C., Frawley, P., \& Ramcharan, P. (2014). Conceptualizing inclusive research with people with intellectual disability. Journal of Applied Research in Intellectual Disabilities, 27(1), 3-12. https://doi-org.proxy.library.uu.nl/1111/jar.12083

Blunt, C., Blyth, C., Chapman, R., Frost, L., Hayward, D., Hughes, R., ... Townson, L. (2012). Editorial. British Journal of Learning Disabilities, 40(2), 83-84. https://doiorg.proxy.library.uu.nl/10.1111/j.1468-3156.2012.00748.x

Cardol, M., Speet, M., \& Rijken, M. (2007). Anders of toch niet? Deelname aan de samenleving van mensen met een lichte of matige verstandelijke beperking: NIVEL.

Dusseljee, J. C. E., Rijken, P. M., Cardol, M., Curfs, L. M. G., \& Groenewegen, P. P. (2010). Participation in daytime activities among people with mild or moderate intellectual disability. 
Frankena, T.K., Naaldenberg, J., Bekkema, N., Schrojenstein Lantman-de Valk, H.J.M. van, Cardol, M., Leusink, G. An exploration of the participation of people with intellectual disabilities in research: a structured interview survey. Journal of Applied Research in Intellectual

Disabilities: 2018, 31(5), 942-947

Journal of Intellectual Disability Research, 55, 4-18. https://doiorg.proxy.library.uu.nl/10.1111/j.1365-2788.2010.01342.x

Finlay, M. (2015). Using questions with people with intellectual disabilities, From client to participant conference. Nijmegen.

Finlay, W. M., \& Lyons, E. (2001). Methodological issues in interviewing and using self-report questionnaires with people with mental retardation. Psychological Assessement, 13(3), 319-335. https://doi-org.proxy.library.uu.nl/10.1037//1040-590.13.3.319

Frankena, T. K., Naaldenberg, J., Cardol, M., Linehan, C., \& Lantman Van Schrojenstein de Valk, H. (2015). Inclusive health research with people with intellectual disabilities - A structured literature review. Research in Developmental Disabilities, 45-46, 271-283. https://doi-org.proxy.library.uu.nl/10.1016/j.ridd.2015.08.004

Grant, G., \& Ramcharan, P. (2007). Valuing people and research: The learning disability research initiative overview report. Waterloo, ON, Department of Health.

INVOLVE (2014). Briefing note seven: Approaches to public involvement in research. Retrieved 3rd of February 2017, from http://www.invo.org.uk/posttyperesource/approachesto-public-involvement/

Nind, M., \& Vinha, H. (2014). Doing research inclusively: bridges to multiple possibilities in inclusive research. British Journal of Learning Disabilities, 42(2), 102-109. https://doiorg.proxy.library.uu.nl/10.1111/bld.12013

NIVEL (2015). Panel Samen Leven. Retrieved 3rd of February 2017, from

https://www.nivel.nl/nl/panel-samen-leven-1

Puyalto, C., Pallisera, M., Fullana, J., \& Vila, M. (2015). Doing research together: A study on the views of advisors with intellectual disabilities and non-disabled researchers collaborating in research. Journal in Applied Research in Intellectual Disabilities, 29(2), 146-159. https://doi-org.proxy.library.uu.nl/10.1111/jar.12165

Shakespeare, T., \& Watson, N. (2002). The social model of disability: An outdated ideology? Exploring theories and expanding methodologies. Research in Social Science and Disability, 2, 9-28.

United Nations (2006). Convention on the rights of persons with disabilities. Retrieved 18 September, 2017, from https://www.un.org/development/desa/disabilities/convention-onthe-rights-of-persons-with-disabilities/convention-on-the-rights-of-persons-with-disabilities2.html

Walmsley, J., \& Johnson, K. (2003). Inclusive research with people with learning disabilities: Past, present and futures. London: Jessica Kingsley Publishers.

Wilson, P., Mathie, E., Keenan, J., McNeilly, E., Goodman, C., Howe, A., ... Peckham, S. (2015). ReseArch with patient and public involvement: a RealisT evaluation - the RAPPORT study. Health Services and Delivery Research, 3(38). 
Frankena, T.K., Naaldenberg, J., Bekkema, N., Schrojenstein Lantman-de Valk, H.J.M. van, Cardol, M., Leusink, G. An exploration of the participation of people with intellectual disabilities in research: a structured interview survey. Journal of Applied Research in Intellectual Disabilities: 2018, 31(5), 942-947

\section{TABLE EN BOX}

\section{BOX 1. PLT QUESTIONS ON PARTICIPATION IN SCIENTIFIC RESEARCH}

1. Have you ever participated in a scientific study besides the Panel Living Together? (If 'no', continue with question 3, otherwise continue with question2)

2. I will now state a number of ways in which you can participate in a scientific study. I would like to know whether you have actually participated in any of the following ways. (Multiple answers are possible)

1. Physical tests or examinations?

2. A questionnaire (online or on paper)?

3. A one-to-one conversation with a researcher? This is also called an interview. For example, the Panel Living Together.

4. A group interview with a researcher together with other people with intellectual disabilities, carers, and/or doctors for example?

5. An advisory board or client council?

6. Working as a researcher, for example by interviewing people with intellectual disabilities or carers together with a researcher?

3. I will now state a number of reasons for participating in a scientific study including the Panel Living Together. I would like to know why you participated in a scientific study. (Multiple answers are possible)

1. Did you expect to enjoy it?

2. Did you want to learn something from it?

3. Did you think the research was important?

4. Did you want to become a more confident person?

5. Did you want to have something to do?

4. Do you want to be informed about the results of the scientific study?

5. What do you want to know about the results of the scientific study?

Table 1. PLT respondents' descriptives in $2014(n=508)$

\begin{tabular}{|l|l|l|l||}
\hline \multicolumn{1}{|c|}{ Variable } & \multicolumn{1}{|c|}{ Answer category } & $N$ & \multicolumn{1}{|c|}{$\begin{array}{c}\text { Valid per } \\
\text { cent }\end{array}$} \\
\hline \hline \multirow{2}{*}{ Sex } & Man & 289 & 56.9 \\
\cline { 2 - 4 } & Woman & 219 & 43.1 \\
\hline \hline \multirow{3}{*}{ Age } & $15-39$ years & 168 & 33.1 \\
\cline { 2 - 4 } & $40-64$ years & 268 & 52.8 \\
\hline \hline \multirow{2}{*}{$\begin{array}{l}\text { Level of intellectual } \\
\text { disabilities }\end{array}$} & 65+ year & 72 & 14.2 \\
\hline \hline \multirow{3}{*}{ Housing } & Mild & 311 & 61.2 \\
\cline { 2 - 4 } & Moderate & 197 & 38.8 \\
\hline
\end{tabular}


Frankena, T.K., Naaldenberg, J., Bekkema, N., Schrojenstein Lantman-de Valk, H.J.M. van, Cardol, M., Leusink, G. An exploration of the participation of people with intellectual disabilities in research: a structured interview survey. Journal of Applied Research in Intellectual Disabilities: 2018, 31(5), 942-947

\begin{tabular}{|l||l||l||l||}
\hline \multicolumn{1}{|c|}{ Variable } & \multicolumn{1}{|c|}{ Answer category } & $N$ & $\begin{array}{l}\text { Valid per } \\
\text { cent }\end{array}$ \\
\hline & Support & & \\
\hline $\begin{array}{l}\text { Independent in community, without } \\
\text { support }\end{array}$ & 34 & 6.7 \\
\hline Family & 25 & 4.9 \\
\hline Other & 5 & 1.0 \\
\hline Unknown & 70 & 13.8 \\
\hline
\end{tabular}

Some data are missing as respondents were not obliged to answer every question to complete the survey. Therefore, valid percentages and number of respondents are presented.

Table 2. Frequency and ways to participate in research other than PLT $(\mathrm{n}=60)$

\begin{tabular}{|c|c|c|c|}
\hline Method & Answer category & $N$ & Valid per cent $(n=60)$ \\
\hline \multirow{3}{*}{ Questionnaires } & Yes & 40 & 66.7 \\
\hline & No & 17 & 28.3 \\
\hline & I don't know & 3 & 5.0 \\
\hline \multirow{3}{*}{ Interviews } & Yes & 34 & 56.7 \\
\hline & No & 23 & 38.3 \\
\hline & I don't know & 3 & 5.0 \\
\hline \multirow{3}{*}{ Physical tests or examinations } & Yes & 29 & 48.3 \\
\hline & No & 28 & 46.7 \\
\hline & I don't know & 3 & 5.0 \\
\hline \multirow{3}{*}{ Advisory boards } & Yes & 26 & 43.3 \\
\hline & No & 31 & 51.7 \\
\hline & I don't know & 3 & 5.0 \\
\hline \multirow{3}{*}{ Focus groups } & Yes & 16 & 26.7 \\
\hline & No & 41 & 68.3 \\
\hline & I don't know & 3 & 5.0 \\
\hline \multirow{3}{*}{ Working as a co-researcher } & Yes & 7 & 11.7 \\
\hline & No & 51 & 85.0 \\
\hline & I don't know & 2 & 3.3 \\
\hline
\end{tabular}

Some data are missing as respondents were not obliged to answer every question to complete the survey. Therefore, valid percentages and number of respondents are presented.

Table 3. Motivation to participate $(n=471 ; 92.7 \%)$

\begin{tabular}{||l||l|l|l||}
\hline \hline \multicolumn{1}{|c|}{ Motivation } & Answer category & $\boldsymbol{N}$ & \begin{tabular}{|} 
Valid per \\
cent
\end{tabular} \\
\hline \hline \multirow{3}{*}{ Did you expect to enjoy it? } & Yes & 346 & 73.5 \\
\hline & No & 21 & 4.5 \\
\hline & I don't know & 75 & 15.9 \\
\hline
\end{tabular}


Frankena, T.K., Naaldenberg, J., Bekkema, N., Schrojenstein Lantman-de Valk, H.J.M. van, Cardol, M., Leusink, G. An exploration of the participation of people with intellectual disabilities in research: a structured interview survey. Journal of Applied Research in Intellectual

Disabilities: 2018, 31(5), 942-947

\begin{tabular}{|c|c|c|c|}
\hline Motivation & Answer category & $N$ & $\begin{array}{l}\text { Valid per } \\
\text { cent }\end{array}$ \\
\hline & $\begin{array}{l}\text { I can't answer the } \\
\text { question }\end{array}$ & 29 & 6.2 \\
\hline & Total & 471 & 100 \\
\hline \multirow{5}{*}{ Did you find research important? } & Yes & 312 & 71.6 \\
\hline & No & 21 & 4.8 \\
\hline & I don't know & 100 & 22.9 \\
\hline & $\begin{array}{l}\text { I can't answer the } \\
\text { question }\end{array}$ & $\mid 3$ & $\mid 0.7$ \\
\hline & Total & 436 & 100 \\
\hline \multirow{5}{*}{ Did you want to learn from it? } & Yes & 212 & 48.0 \\
\hline & No & 101 & 22.9 \\
\hline & I don't know & 123 & 27.8 \\
\hline & $\begin{array}{l}\text { I can't answer the } \\
\text { question }\end{array}$ & |6 6 & $\mid 1.4$ \\
\hline & Total & 442 & 100 \\
\hline \multirow{5}{*}{$\begin{array}{l}\text { Did you want to become a more confident } \\
\text { person? }\end{array}$} & Yes & 166 & 38.3 \\
\hline & No & 89 & 20.6 \\
\hline & I don't know & 177 & 40.9 \\
\hline & $\begin{array}{l}\text { I can't answer the } \\
\text { question }\end{array}$ & $\| 1$ & $\mid 0.2$ \\
\hline & Total & 433 & 100 \\
\hline \multirow{5}{*}{ Did you want something to do? } & Yes & 138 & 31.9 \\
\hline & $\mathrm{No}$ & 170 & 38.4 \\
\hline & I don't know & 120 & 27.8 \\
\hline & $\begin{array}{l}\text { I can't answer the } \\
\text { question }\end{array}$ & 4 & $\mid 0.9$ \\
\hline & Total & 432 & 100 \\
\hline
\end{tabular}

Some data are missing as respondents were not obliged to answer every question to complete the survey. Therefore, valid percentages and number of respondents are presented. 